\title{
FAKTOR-FAKTOR YANG BERHUBUNGAN DENGAN TINGKAT PENGETAHUAN TENTANG LEUKEMIA ANAK PADA PETUGAS KESEHATAN PUSKESMAS MANADO
}

\author{
${ }^{1}$ Fransisca Sepang \\ ${ }^{2}$ Stefanus Gunawan \\ ${ }^{3}$ Vivekenanda Pateda \\ Bagian Ilmu Kesehatan Anak Universitas Sam Ratulangi \\ Email: sisca_sepang@yahoo.com
}

\begin{abstract}
Leukemia is one of leading causes of death among children. Limited knowledge of healthcare providers is the cause of non-compliance treatment protocol leukemia. To comply the protocol, health-care providers must have adequate knowledge regarding diagnostic, treatment and therapeutic procedures. This research aimed to understand level of knowledge and factors related to knowledge about childhood leukemia which are age, educational level and experience of work on the healthcare providers Manado Primary Health Center. This research used descriptive analytic cross sectional study using structured questionnaire. Cronbrach's Alpha value obtained 0.969. Respondents were 114 health-care providers working at Manado Primary Health Center, attained by cluster sampling method. Based on the frequency distribution majority of respondents had a good knowledge. The results of Chi Square test obtained three variables that have a significant relationship with level of knowledge which are age $(\mathrm{x} 2=10.413, \mathrm{p}=0.005)$, educational level $(\mathrm{x} 2=$ $6.401, \mathrm{p}=0.041)$ and experience of work $(\mathrm{x} 2=6.270, \mathrm{p}=0.044)$. Majority of health-care providers Manado Primary Health Center had a good knowledge of childhood leukemia and knowledge related to age, level of education and experience of work.
\end{abstract}

Keywords: Leukemia, Knowledge, Health-care providers.

Abstrak: Leukemia merupakan kanker paling banyak dan penyebab utama kematian pada anak. Terbatasnya pengetahuan tenaga kesehatan merupakan penyebab dari ketidakpatuhan terhadap protokol pengobatan leukemia. Untuk memenuhi protokol tersebut, tenaga kesehatan harus memiliki pengetahuan yang cukup mengenai diagnostik, penatalaksanaan dan prosedur pengobatan. Penelitian ini bertujuan untuk mengetahui tingkat pengetahuan dan faktor-faktor yang berhubungan dengan tingkat pengetahuan tentang leukemia yaitu umur, tingkat pendidikan dan lama bekerja.anak pada petugas kesehatan Puskesmas Manado. Penelitian ini bersifat deskriptif analitik dengan rancangan penelitian studi potong lintang menggunakan kuesioner terstruktur. Nilai Alpha Cronbrach yang diperoleh 0,969. Responden dalam penelitian ini 114 petugas kesehatan yang didapatkan dengan metode Cluster Sampling. Berdasarkan hasil distribusi frekuensi mayoritas responden memiliki pengetahuan baik. Hasil uji Chi Square didapat 3 variabel yang berhubungan signifikan dengan tingkat pengetahuan yaitu umur (x2 = 10,413; $\mathrm{p}=0,005)$, tingkat pendidikan $(\mathrm{x} 2=6,401 ; \mathrm{p}=0,041)$ dan lama bekerja $(\mathrm{x} 2=6,270 ; \mathrm{p}=$ 0,044). Mayoritas petugas kesehatan Puskesmas Manado memiliki pengetahuan baik tentang leukemia pada anak dan pengetahuan tersebut berhubungan dengan umur, tingkat pendidikan dan lama bekerja.

Kata kunci: Leukemia, Pengetahuan, Petugas Kesehatan. 
Leukemia merupakan kanker paling banyak dan penyebab utama kematian pada anakanak usia antara 1 dan 14 tahun. $^{1}$ Pada tahun 2004 di Amerika Serikat, diantara anak-anak berusią14 tahun, tingkat kejadian kanker dan tingkat kematian per 100.000 populasi yaitu 14,8 dan $2,5 .^{2}$

Pada tahun 2010, di Pusat Kanker Anak Estella Manado telah mengobati 60 pasien baru dari berbagai daerah di Indonesia Timur seperti Papua, Maluku, Maluku Utara (Ternate) dan Gorontalo. ${ }^{3}$

Leukemia limfoblastik akut merupakan bentuk leukemia terbanyak pada anakanak. Sekitar 68,5\% dari seluruh kasus terjadi pada anak antara usia 2-10 tahun. ${ }^{4}$ Pada Leukemia mieloblastik akut (LMA) diperkirakan menyumbang sebanyak 1525\% dari seluruh kasus leukemia akut pada anak usia $<15$ tahun. $^{5}$

Di Indonesia penyebab kegagalan pengobatan LLA antara lain yaitu penolakan pengobatan, kematian akibat toksisitas, dan ketidakpatuhan terhadap protokol pengobatan. Terbatasnya pengetahuan, kurangnya kesadaran dan pengenalan terhadap penyakit oleh orang tua pasien dan penyedia layanan kesehatan merupakan penyebab dari ketidakpatuhan terhadap protokol pengobatan. Untuk memenuhi protokol tersebut, penyedia layanan kesehatan harus memiliki pengetahuan yang cukup mengenai syarat-syarat diagnostik, penatalaksanaan dari diagnosis dan prosedur pengobatan yang tepat. ${ }^{6}$

\section{TUJUAN}

Tujuan dari penelitian ini yaitu untuk mengetahui tingkat pengetahuan tentang leukemia anak pada petugas kesehatan Puskesmas Manado serta mengetahui faktor-faktor yang berhubungan dengan tingkat pengetahuan tentang leukemia anak yaitu umur, tingkat pendidikan dan lama bekerja pada petugas kesehatan Puskesmas Manado.

\section{METODE}

\section{Desain penelitian}

Penelitian ini merupakan penelitian deskriptif analitik dengan menggunakan rancangan penelitian studi potong lintang (cross sectional study). Penelitian ini hanya dilakukan satu kali, pada petugas puskesmas di Manado.

\section{Tempat dan waktu penelitian}

Penelitian ini dilakukan di Puskesmas Kota Manado, selama periode bulan November-Desember 2012.

\section{Sampel}

Sampel merupakan penderita PJK yang didapatkan dengan teknik 85 responden minimal yang dibutuhkan. Teknik pengambilan sampel dengan teknik Cluster Sampling.

\section{Variabel penelitian}

Variabel indepeden pada penelitian ini yaitu Tingkat Pengetahuan dan variabel dependen yaituu umur, tingkat pendidikan, dan lama bekerja.

\section{Uji validitas dan reliabilitas}

Dalam penelitian ini, uji validitas dianalisis dengan menggunakan Pearson Correlation. Dari 20 item yang diujikan kepada 10 orang responden, terdapat 16 item yang valid.

Dari uji reliabilitas diperoleh nilai Alpha Cronbrach $(\alpha)$ sebesar 0,969. Suatu instrumen dikatakan sangat reliabel jika nilai Alpha Cronbrach $(\alpha)$ berkisar antara 0,801-1.00, maka item-item pertanyaan variabel pengetahuan leukemia pada anak dinyatakan dinyatakan sangat reliabel.

\section{Pengumpulan data}

Data primer meliputi identitas subjek penelitian dan pengetahuan petugas kesehatan terhadap leukemia diperoleh dengan menggunakan kuesioner. Untuk 
perhitungan diukur dengan menggunakan rumus:

$\mathrm{P}=\mathrm{F} / \mathrm{N} \times 100 \%$

Keterangan:

$\mathrm{P} \quad=$ Nilai yang didapat

$\mathrm{F} \quad=$ Jumlah jawaban yang benar

$\mathrm{N} \quad=$ Jumlah soal

Hasilnya kemudian diinterpretasikan pada kriteria:

Baik :Bila skor yang diperoleh 76-100\% Cukup :Bila skor yang diperoleh 50-75\% Kurang :Bila skor yang diperoleh $<50 \%$

Data sekunder mengenai jumlah tenaga kesehatan di Puskesmas Manado yang diperoleh dari Dinas Kesehatan Kota Manado.

\section{Teknik Analisis Data}

Data dianalisis dengan menggunakan komputer program SPSS versi 20. Analisa univariat dilakukan distribusi frekuensi pada tiap variabel. Analisa bivariat dilakukan dengan menggunakan uji statistik Chi-Square, dengan tingkat kemaknaan $95 \%(\alpha=0,05)$.

\section{HASIL}

\section{Karakteristik responden}

Berdasarkan hasil analisis distribusi frekuensi dapat dilihat pada tabel 1, mayoritas responden pada kategori umur 31-40 tahun. Sebagian besar responden merupakan lulusan Diploma III. Sebagian besar responden telah bekerja antara 1-5 tahun.

\section{Tingkat pengetahuan}

Berdasarkan hasil analisis distribusi frekuensi dapat dilihat pada tabel 2 dan gambar 1 dapat dilihat bahwa sebagian besar responden memiliki pengetahuan baik dan yang paling sedikit memiliki pengetahuan kurang.
Tabel 1. Karakteristik Responden

\begin{tabular}{lcc}
\hline $\begin{array}{l}\text { Karakteristik } \\
\text { Responden }\end{array}$ & $\begin{array}{c}\text { Jumlah } \\
\text { (n) }\end{array}$ & $\begin{array}{c}\text { Persentase } \\
\text { (\%) }\end{array}$ \\
\hline Umur & & \\
$\quad$ 21-30 tahun & 40 & 35,1 \\
31-40 tahun & 48 & 42,1 \\
41-50 tahun & 12 & 10,5 \\
$\quad$ >50 tahun & 14 & 12,3 \\
Tingkat Pendidikan & & \\
$\quad$ SMA/sederajat & 30 & 26,3 \\
$\quad$ Diploma I & 2 & 1,8 \\
Diploma III & 52 & 45,6 \\
S1 & 30 & 26,3 \\
Lama Bekerja & & \\
1-5 tahun & 41 & 36,0 \\
6-10 tahun & 18 & 15,8 \\
11-15 tahun & 20 & 17,5 \\
16-20 tahun & 12 & 10,5 \\
> 20 tahun & 23 & 20,2 \\
\hline
\end{tabular}

Tabel 2. Distribusi tingkat pengetahuan responden

\begin{tabular}{lcc}
\hline $\begin{array}{c}\text { Tingkat } \\
\text { Pengetahuan }\end{array}$ & $\begin{array}{c}\text { Jumlah } \\
\text { (n) }\end{array}$ & Persentase (\%) \\
\hline Baik & 79 & 69,3 \\
Cukup & 34 & 29,8 \\
Kurang & 1 & 0,9 \\
\hline \multicolumn{1}{c}{ Total } & 114 & 100 \\
\hline
\end{tabular}

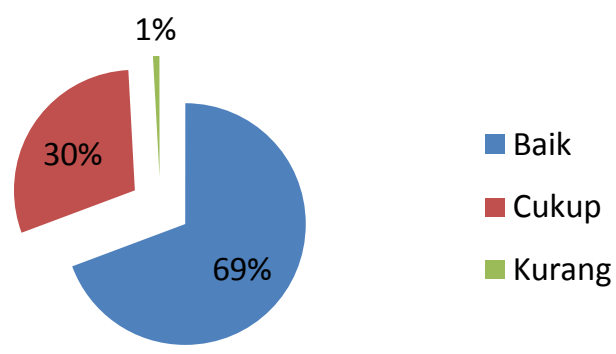

Gambar 1. Distribusi tingkat pengetahuan responden.

\section{Analisis bivariat}

Berdasarkan hasil uji statistik Chi Square dapat dilihat dari tabel 3, kategori umur, tingkat pendidikan dan lama bekerja 
nilai $\mathrm{x}^{2}$ hitung $>\mathrm{x}^{2}$ tabel dan nilai $\mathrm{p}<0,05$, maka Ho ditolak.

Tabel 3. Hasil Analisis Bivariat Faktor-Faktor yang Berhubungan dengan Tingkat Pengetahuan

\begin{tabular}{llcc}
\hline \multicolumn{1}{c}{ Variabel } & \multicolumn{1}{c}{$\begin{array}{c}\mathbf{X}^{2} \\
\text { hitung }\end{array}$} & $\begin{array}{c}\mathbf{X}^{2} \\
\text { tabel }\end{array}$ & $\mathbf{P}$ \\
\hline Umur & 10,413 & 5,991 & 0,005 \\
Tingkat & 6,401 & 5,991 & 0,041 \\
$\begin{array}{l}\text { pendidikan } \\
\text { Lama bekerja }\end{array}$ & 6,270 & 5,991 & 0,044 \\
\hline
\end{tabular}

\section{DISKUSI}

\section{Hubungan umur petugas kesehatan dan tingkat pengetahuan}

Berdasarkan hasil uji statistik didapatkan bahwa, kategori umur mempunyai hubungan signifikan dengan tingkat pengetahuan. Hal ini sejalan dengan penelitian oleh Ika Suherlin di Medan, yang menyatakan ada hubungan yang signifikan antara umur dengan tingkat pengetahuan. ${ }^{7}$

\section{Hubungan tingkat pendidikan petugas kesehatan dan tingkat pengetahuan}

Berdasarkan hasil uji statistik didapatkan bahwa, tingkat pendidikan mempunyai hubungan signifikan dengan tingkat pengetahuan. Hal ini sejalan dengan penelitian oleh Sara Herlina di Pekanbaru, yang menyimpulkan bahwa ada hubungan antara pendidikan responden dengan tingkat pengetahuan. ${ }^{8}$

\section{Hubungan lama bekerja petugas kesehatan dan tingkat pengetahuan}

Berdasarkan hasil uji statistik didapatkan bahwa, lama bekerja mempunyai hubungan signifikan dengan tingkat pengetahuan. Hal ini sejalan dengan penelitian oleh Ely Puspita di Pekanbaru, yang menyimpulkan bahwa ada hubungan antara lama bekerja responden dengan tingkat pengetahuan. ${ }^{9}$

\section{Kelemahan penelitian}

Responden penelitian merupakan tenaga kesehatan yang sedang bekerja di Puskesmas. Pada saat proses pengambilan data dilakukan, responden sedang dalam jam kerja sementara itu diminta untuk mengisi kuesioner, terdapat kemungkinan responden sedang sibuk atau lelah. Sehingga data penelitian dapat menjadi bias.

Kelemahan lain dari penelitian ini yakni pada waktu pengumpulan data, setelah diberi penjelasan seperlunya responden penelitian dipersilahkan untuk mengisi kuesioner, terdapat kemungkinan responden bertanya atau berdiskusi dengan tenaga kesehatan yang lain, sehingga data penelitian dapat menjadi bias.

\section{SIMPULAN}

Berdasarkan hasil penelitian dan pembahasan maka dapat diambil simpulan bahwa mayoritas petugas kesehatan Puskesmas Manado memiliki pengetahuan baik tentang leukemia pada anak dan pengetahuan tersebut berhubungan dengan umur, tingkat pendidikan dan lama bekerja.

\section{SARAN}

Diharapkan kepada petugas kesehatan di Puskesmas Manado untuk mempertahankan serta meningkatkan pengetahuan/kewaspadaan dan deteksi dini leukemia anak

Bagi ilmu pengetahuan sebaiknya penelitian mengenai tingkat pengetahuan petugas kesehatan dan leukemia anak diperbanyak, khususnya mengenai tingkat pengetahuan tentang leukemia anak pada petugas kesehatan Puskesmas Manado.

Bagi para peneliti yang tertarik untuk melakukan penelitian serupa perlu mempertimbangkan penggunaan metode penelitian yang lain, instrumen yang lebih tepat, serta dapat menyertakan faktor-faktor lain yang berkaitan dan mempengaruhi pengetahuan. 


\section{UCAPAN TERIMA KASIH}

Kepada dr. Johny Rompis, SpA \& dr. Jose Mandei, SpA dan kepada semua pihak yang baik secara langsung ataupun tidak langsung telah menumbuhkan ide atau gagasan pada penulis sehingga penulis dapat menyelesaikan artikel ini

\section{DAFTAR PUSTAKA}

1. Allareddy V, Rampa S, Allareddy V. Hospital charges and length of stay associated with septicemia among children hospitalized for leukemia treatment in the United States. World J Pediatr. 2012;8:222-8.

2. Estella Fonds. Estella Buletin [homepage on the internet]. 2010 [diakses 2012 Okt 24]. Diunduh dari: http://www.estellafonds.nl/custom/bulletin -december.pdf

3. Shalaby RH, Ashaat NA, EI-Wahab NA, El-Hamid MA, El-Wakeel SH. Bel-2 expression and chromosomal abnormalities in childhood acute lymphoblastic leukemia. Acad J Cancer. 2010;3:34-43.

4. Kömür M, Erbey F, Bayram I, Tanyeli A. Incidence and prognostic importance of molecular genetic defects in children with acute myeloblastic leukemia. Asian Pacific J Cancer Prev. 2010;11:1393-5.
5. Chen B, Huang Z, Zhang X, Ou-Yang J, Li J, Zhai YP, et al. An epidemiological investigation of leukemia incidence between 2003 and 2007 in Nanjing, China. J Hematol Oncol. 2010;3:21.

6. Sitaresmi MN, Mostert S, Gundy CM, Sutaryo, Veerman AJP. Health-care providers' compliance with childhood acute lymphoblastic leukemia protocol in Indonesia. Pediatr Blood Cancer. 2008;5:732-6.

7. Suherlin I. Hubungan karakteristik responden dengan tingkat pengetahuan responden tentang gaya hidup yang mempengaruhi infertil di lingkungan III Kelurahan Labuhan Deli Kecamatan Medan Marelan Tahun 2008 (Skripsi). Universitas Sumatera Utara; 2009.

8. Herlina S. Hubungan karakteristik dengan tingkat pengetahuan ibu postpartum tentang perawatan masa nifas di ruang camar I Rumah Sakit Umum Daerah Arifin Achmad Pekanbaru Tahun 2009 (Skripsi). Universitas Sumatera Utara; 2009.

9. Puspita E. Hubungan karakteristik bidan dengan tingkat pengetahuan bidan tentang pencegahan infeksi pada masa nifas di rumah bersalin dan Balai Pengobatan Swasta Wilayah Kerja Puskesmas Sidomulyo Kota Pekanbaru Tahun 2009 (Skripsi). Universitas Sumatera Utara; 2009. 